\section{BMJ Paediatrics Open}

\title{
Pilot evaluation of parental and professional views regarding consent in neonatal medicine by telephone interviews and questionnaires
}

Vimal Vasu

To cite: Vasu V. Pilot evaluation of parental and professional views regarding consent in neonatal medicine by telephone interviews and questionnaires. BMJ Paediatrics Open 2017;1:e000128. doi:10.1136/ bmjpo-2017-000128

- Additional material is published online only. To view please visit the journal online (http://dx.doi.org/10.1136/ bmjpo-2017-000128).

Received 31 May 2017 Revised 20 September 2017 Accepted 16 0ctober 2017

\section{(a) CrossMark}

Department of Neonatal Medicine, William Harvey Hospital, Kent, UK

\section{Correspondence to} Dr Vimal Vasu, Department of Neonatal MedicineWilliam Harvey HospitalKentUK; vimal. vasu@nhs.net

\section{ABSTRACT}

Objective The objectives of the study were to determine (1) parental and professional views regarding the type of consent required for common neonatal interventions and (2) whether there has been a change in professional understanding regarding the requirements of consent since the last UK survey in 2003.

Design Cohort study of (1) parents of babies admitted to a single-centre tertiary neonatal unit and (2) healthcare professionals.

Methods The views of 8 parents of former neonatal patients and 69 neonatal professionals were sought using online and telephone survey methodology regarding 20 neonatal interventions and whether implied consent, explicit verbal consent or explicit written consent should be obtained.

Results Agreement, defined as both parental and professional consensus on the type of consent required, was present in 12/20 of the interventions. Comparison between professional views in 2003 demonstrated a change regarding type of consent for $50 \%$ of interventions with a shift towards obtaining explicit written consent certain treatments.

Conclusions The study indicates areas of consensus that exist between parents and professionals regarding consent for common neonatal interventions and a change in professional views regarding consent since the last UK survey in 2003. These data might help inform the development of national guidance for how professionals should obtain consent in neonatology.

\section{INTRODUCTION}

Admission of a baby to a neonatal unit is anxiety provoking ${ }^{1}$ for parents, and information about interventions may not be understood or retained. Nonetheless, parents may be asked to sanction proposed interventions based on medical 'best interests'. Following admission, additional interventions may be required and often these occur without further discussion with parents. This is justified because treatment is thought to be an emergency. However, in some instances, the treatment may not be an emergency

\section{What is already known on this topic?}

There are limited data exploring parental and professional views regarding consent in neonatal medicine.

- Existing data are now largely historical and have only explored the professional viewpoint.

- Given the recent changes in how the UK courts view the standard of information disclosure, it is important that parental and professional views regarding consent are established in the current era of neonatal medicine.

\section{What this study hopes to add?}

A current and parallel evaluation of parental and professional views regarding consent in neonatal medicine for common interventions.

- There is agreement between parents and professionals for many interventions.

- A change in professional views regarding consent since the last UK survey in 2003.

but rather semi-urgent in nature (figure 1). Therefore, there exists an opportunity to discuss the proposed treatment with parents prior to initiating it.

Guidance regarding consent in neonatology was last published 14 years $^{2}$ ago, and the only UK survey to explore professional views $^{3}$ demonstrated variation in practice. The subject is now of increased relevance given the landmark Supreme Court ruling in the case of Montgomery $v$ Lanarkshire Health Board $^{4}$ in which there was a paradigm shift in judicial opinion, favouring as a standard of information disclosure, the patient standard over the professional standard.

Though data exist on the characteristics of medical decisions that influence parental desire for parental input into decision-making, ${ }^{5}$ there are limited data 


\begin{tabular}{|l|l|}
\hline \multicolumn{1}{|c|}{ Proposed neonatal treatment or intervention } & \multicolumn{1}{c|}{ Comments } \\
\hline Increase in respiratory requirement such as the use of & Within modern NICU monitoring, respiratory \\
humidified high flow nasal cannula oxygen therapy & deterioration can be anticipated. Thus, in a proportion \\
(HHFNC), continuous positive airway pressure (CPAP), & of cases where there is a requirement for increased \\
intubation and mechanical ventilation & respiratory support, there may be time to discuss the \\
\hline Insertion of a nasogastric or orgogastric tube to support & Some newborn infants will require additional feeding \\
the enteral feeding of the newborn & support. In these circumstances, it is common practice \\
for neonatal nursing staff to insert a nasogastric or \\
orogastric tube. Though this might be perceived as an \\
important intervention, it is not an emergency.
\end{tabular}

Figure 1 Two examples of commonly performed neonatal interventions in neonatal units where, despite the intervention not being emergency in nature, the intervention occurs and the family is notified retrospectively. [NICU, neonatal intensive care unit].

exploring contemporaneous parental and professional views regarding consent. Therefore, the objective of this study is to provide pilot data on parental and professional views on consent for common neonatal interventions to better inform clinical practice.

\section{METHODS}

This was a single-centre cohort study (William Harvey Hospital, Ashford, Kent, UK) conducted between June and November 2016 to test the hypothesis that there is discordance between parental and professional views on whether implicit, explicit verbal or explicit written consent should be obtained for common neonatal interventions. The interventions were chosen both pragmatically and to reflect those that had been considered in the 2004 British Association of Perinatal Medicine guidelines. ${ }^{2}$

\section{Survey of parental opinion}

Parents of babies admitted to the regional level 3 neonatal unit at the William Harvey Hospital, Ashford, Kent, UK, were identified through the neonatal unit admissions register. The parents of the first eligible admission for each month during 2015 were contacted and invited to participate. If parents declined participation, the parents of the next eligible admission were contacted. Overall, 14 parents were invited to participate and 8 parents were recruited to the study. Parents were invited to participate via telephone or while attending routine hospital outpatient clinic appointments, provided with a parent information leaflet and informed written consent obtained. Telephone or face-to-face interviews were conducted based on parental preference using a pre-designed interview questionnaire to ensure that parents understood the different types of consent and the interventions being discussed along with foreseeable risks and benefits (online supplementary file $1)$.

\section{Inclusion criteria}

- Admitted to neonatal unit in 2015

- Gestational age at birth $>32$ weeks

- Discharge date from neonatal unit $>2$ months

\section{Exclusion criteria}

Parents of babies not fulfilling the above inclusion criteria

\section{Survey of professional opinion}

Professionals' views (consultant neonatologist, junior doctors and neonatal advanced neonatal nurse practitioner) were sought. Telephone interviews were conducted with 4 consultant neonatologists to establish qualitative data alongside a SurveyMonkey (https://www.surveymonkey. com) questionnaire of 65 other professionals.

\section{Data analysis}

Quantitative data

Consensus between parents and professionals was assessed by the percentage of respondents in each group choosing implied consent, explicit verbal consent or explicit written consent. Implicit consent refers to clinicians proceeding with the intervention without necessarily having any a priori discussion with the parents. 
Explicit consent was either a verbal discussion with the parents prior to performing the intervention (explicit verbal) or actual written consent prior to initiating the intervention with a parental signature documented (explicit written). Where a clear preference existed within the groups, this was taken as consensus. Parent and professional consensus views for each intervention were then compared for agreement. Discordance between the groups was defined as consensus in less than $10 / 20(50 \%)$ of interventions.

Differences in professional views between the 2003 survey $^{3}$ and the current survey were assessed using a $\chi^{2}$ test. A Bonferroni correction was applied in view of multiple comparisons (IBM 2016, V.24.0; IBM, Armonk, New York, USA).

\section{Qualitative data}

Thematic content analysis of data was conducted to identify and analyse themes. ${ }^{6}$ Inductive analysis was used without any a priori hypotheses being considered and group themes compared.

\section{RESULTS}

\section{Quantitative data}

Quantitative data were obtained from eight parents (table 1). $17 / 20(85 \%)$ interventions resulted in a consensus view being achieved for type of consent. No interventions elicited a consensus view for explicit written consent. However, there was a degree of variation in parental views on which type of consent should be obtained for the interventions in the study with 12/20 (60\%) and 8/20 (40\%) interventions eliciting answers including three or two types of consent, respectively.

Quantitative data were obtained from 69 professionals (table 2). All interventions resulted in consensus for type of consent. No interventions elicited a consensus view for explicit written consent. However, there was evidence of variation in clinician views on which type of consent should be obtained for the interventions in the study questionnaire with 15 and 5 treatments eliciting answers including all three types of consent and two different types of consent, respectively.

\section{Agreement between parental and professional views}

Consensus regarding consent was obtained for $17 / 20$ $(85 \%)$ interventions in the parent group and 20/20 $(100 \%)$ interventions in the professional group. Agreement, defined as both parental and professional consensus on type of consent, was present in 12/20 $(60 \%)$ interventions (table 3$)$.

\section{Comparison with historical data}

Professionals' data were compared with those of the previous UK survey (3) by analysis of the rates of implied consent (table 4). There were 10 treatments in common between the two surveys. There was a change in view for five interventions between the surveys, with a move
Table 1 Parental views on consent for 20 neonatal interventions $(n=8)$

\begin{tabular}{|c|c|c|c|}
\hline Intervention & $\begin{array}{l}\text { Implied } \\
\text { consent }\end{array}$ & $\begin{array}{l}\text { Explicit } \\
\text { verbal } \\
\text { consent }\end{array}$ & $\begin{array}{l}\text { Explicit } \\
\text { written } \\
\text { consent }\end{array}$ \\
\hline $\begin{array}{l}\text { Peripheral intravenous } \\
\text { cannulation }\end{array}$ & 6 & 2 & 0 \\
\hline $\begin{array}{l}\text { Peripheral arterial line } \\
\text { insertion }\end{array}$ & 3 & 5 & 0 \\
\hline Lumbar puncture & 2 & 5 & 1 \\
\hline Endotracheal intubation & 5 & 3 & 0 \\
\hline $\begin{array}{l}\text { Central venous catheter } \\
\text { insertion (long line) }\end{array}$ & 2 & 6 & 0 \\
\hline Umbilical catheter insertion & 4 & 3 & 1 \\
\hline $\begin{array}{l}\text { Scalp vein insertion } \\
\text { (cannula or long line) }\end{array}$ & 2 & 5 & 1 \\
\hline Surfactant administration & 6 & 1 & 1 \\
\hline Intercostal drain insertion & 5 & 3 & 0 \\
\hline $\begin{array}{l}\text { Suprapubic aspiration of } \\
\text { urine }\end{array}$ & 2 & 5 & 1 \\
\hline Use of nitric oxide & 4 & 4 & 0 \\
\hline Blood transfusion & 2 & 5 & 1 \\
\hline $\begin{array}{l}\text { Dilutional exchange } \\
\text { transfusion }\end{array}$ & 3 & 2 & 3 \\
\hline $\begin{array}{l}\text { Double volume exchange } \\
\text { transfusion }\end{array}$ & 2 & 3 & 3 \\
\hline $\begin{array}{l}\text { Pharmacological closure of } \\
\text { a patent ductus arteriosus }\end{array}$ & 3 & 4 & 1 \\
\hline $\begin{array}{l}\text { Use of postnatal steroids } \\
\text { to facilitate extubation from } \\
\text { ventilator in preterm infants }\end{array}$ & 5 & 3 & 0 \\
\hline $\begin{array}{l}\text { Urine toxicology to screen } \\
\text { for drugs of abuse }\end{array}$ & 7 & 1 & 0 \\
\hline $\begin{array}{l}\text { DNA CGH array or other } \\
\text { specific genetic testing }\end{array}$ & 3 & 4 & 1 \\
\hline Therapeutic hypothermia & 5 & 1 & 2 \\
\hline $\begin{array}{l}\text { Ventricular tap (for } \\
\text { posthaemorrhagic } \\
\text { hydrocephalus) }\end{array}$ & 3 & 4 & 1 \\
\hline
\end{tabular}

towards obtaining explicit written consent for central line insertion, lumbar punctures, suprapubic aspiration, genetic testing and blood transfusion.

\section{Qualitative data}

Thematic content analysis of parental data $(n=8)$ revealed the following four key themes.

\section{Trust in professional advice and deference to advice}

One of the strongest themes to emerge from interviewing parents was the trust that they placed in the medical team looking after their baby. The following excerpts illustrate this:

Do whatever you need to. 
Table 2 Professional views on consent for 20 neonatal interventions $(n=69)$

\begin{tabular}{|c|c|c|c|c|c|c|}
\hline \multirow[b]{2}{*}{ Intervention } & \multicolumn{2}{|c|}{ Implied consent } & \multicolumn{2}{|c|}{ Explicit verbal consent } & \multicolumn{2}{|c|}{$\begin{array}{l}\text { Explicit written } \\
\text { consent }\end{array}$} \\
\hline & $\mathbf{n}$ & $\%$ & n & $\%$ & $\bar{n}$ & $\%$ \\
\hline Peripheral intravenous cannulation & 66 & 96 & 3 & 4.3 & 0 & 0.0 \\
\hline Peripheral arterial line insertion & 49 & 71 & 19 & 27.5 & 1 & 1.4 \\
\hline Lumbar puncture & 19 & 27.5 & 48 & 70 & 2 & 2.9 \\
\hline Endotracheal intubation & 58 & 84 & 11 & 15.9 & 0 & 0.0 \\
\hline Central venous catheter insertion (long line) & 45 & 65 & 23 & 33.3 & 1 & 1.4 \\
\hline Umbilical catheter insertion & 57 & 83 & 12 & 17.4 & 0 & 0.0 \\
\hline Scalp vein insertion (cannula or long line) & 33 & 47.8 & 35 & 51 & 1 & 1.4 \\
\hline Surfactant administration & 62 & 90 & 7 & 10.1 & 0 & 0.0 \\
\hline Intercostal drain insertion & 52 & 75 & 15 & 21.7 & 2 & 2.9 \\
\hline Suprapubic aspiration of urine & 43 & 62 & 26 & 37.7 & 0 & 0.0 \\
\hline Use of nitric oxide & 54 & 78 & 14 & 20.3 & 1 & 1.4 \\
\hline Blood transfusion & 25 & 36.2 & 28 & 41 & 16 & 23.2 \\
\hline Dilutional exchange transfusion & 18 & 26.1 & 35 & 51 & 16 & 23.2 \\
\hline Double volume exchange transfusion & 11 & 15.9 & 31 & 45 & 27 & 39.1 \\
\hline Pharmacological closure of a patent ductus arteriosus & 17 & 24.6 & 47 & 68 & 5 & 7.2 \\
\hline $\begin{array}{l}\text { Use of postnatal steroids to facilitate extubation from ventilator in } \\
\text { preterm infants }\end{array}$ & 9 & 13.0 & 52 & 75 & 8 & 11.6 \\
\hline Urine toxicology to screen for drugs of abuse & 18 & 26.1 & 42 & 61 & 9 & 13.0 \\
\hline DNA CGH array or other specific genetic testing & 1 & 1.4 & 42 & 61 & 26 & 37.7 \\
\hline Therapeutic hypothermia & 45 & 65 & 21 & 30.4 & 3 & 4.3 \\
\hline Ventricular tap (for posthaemorrhagic hydrocephalus) & 19 & 27.5 & 36 & 52 & 14 & 20.3 \\
\hline
\end{tabular}

Table 3 Consensus (highlighted in bold and green) among parents and professionals choosing implied, explicit verbal or explicit written consent for each intervention

\begin{tabular}{ll}
\hline Interventions & Consensus view \\
\hline Peripheral intravenous cannula & Implied consent \\
Peripheral arterial line & No consensus \\
Lumbar puncture & Explicit verbal \\
Endotracheal intubation & Implied consent \\
Long line & No consensus \\
Umbilical catheter & Implied consent \\
Scalp vein & Explicit verbal \\
Surfactant & Implied consent \\
\hline Intercostal drain & Implied consent \\
\hline Suprapubic aspiration & No consensus \\
\hline Nitric oxide & No consensus \\
Blood transfusion & Explicit verbal \\
\hline Dilutional exchange transfusion & No consensus \\
Double volume exchange transfusion & No consensus \\
\hline Medical closure of patent ductus arteriosus & Explicit verbal \\
\hline Postnatal steroids for extubation & No consensus \\
Urine toxicology & No consensus \\
\hline DNA CGH array & Explicit verbal \\
Therapeutic hypothermia & Implied consent \\
Ventricular tap & Explicit verbal \\
\hline
\end{tabular}

Agreement between parent and professional choice in type of consent is illustrated in green (12/20: $60 \%)$.
Go ahead and do what is necessary.

Parental instinct is to rely on what doctors say.

Time

Parents commented that whether an intervention was emergency or not should dictate how information is provided to them. Many parents expressed the view that where there was time, they would value a discussion including options, risks and benefits.

As one parent commented:

Forewarned is forearmed.

Another parent raised the concern that they would feel angry if they had not been warned of potential risks if a complication subsequently occurred.

\section{Burden of decision-making}

Some parents indicated that imposing 'too much' decision-making responsibility on parents may not be welcome and that they would value the final decision to be made by the medical team. One parent describes this as follows:

Doctors take on the stress (of decision making) for parents.

Mixed information

Mixed information regarding potential interventions emerged as a theme. While on neonatal units, parents were given different information by different 
Table 4 Comparison of survey results regarding professional views on consent in neonatal units between 2003 and 2016 $(n=10)$

\begin{tabular}{|c|c|c|c|c|c|c|c|}
\hline & \multicolumn{3}{|c|}{2003 (Shenoy) } & \multicolumn{3}{|l|}{2016 (Vasu) } & \multirow[b]{2}{*}{ p Value } \\
\hline & $\begin{array}{l}\text { Implied } \\
\text { consent (n) }\end{array}$ & $\begin{array}{l}\text { Explicit } \\
\text { consent (n) }\end{array}$ & $\begin{array}{l}\text { Implied } \\
\text { consent (\%) }\end{array}$ & $\begin{array}{l}\text { Implied } \\
\text { consent (n) }\end{array}$ & $\begin{array}{l}\text { Explicit } \\
\text { consent (n) }\end{array}$ & $\begin{array}{l}\text { Implied } \\
\text { consent (\%) }\end{array}$ & \\
\hline Peripheral intravenous cannula & 46 & 1 & 98 & 66 & 3 & 96 & 0.646 \\
\hline Central line insertion (long line) & 43 & 4 & 91 & 45 & 24 & 65 & $0.002^{*}$ \\
\hline Lumbar puncture & 39 & 8 & 83 & 19 & 50 & 28 & $<0.0001^{*}$ \\
\hline Suprapubic aspirate & 41 & 5 & 89 & 43 & 26 & 62 & $0.001^{\star}$ \\
\hline Intercostal chest drain & 40 & 6 & 87 & 52 & 17 & 75 & 0.157 \\
\hline Endotracheal intubation & 44 & 3 & 94 & 58 & 11 & 84 & 0.153 \\
\hline Surfactant & 44 & 2 & 96 & 62 & 7 & 90 & 0.312 \\
\hline Nitric oxide & 23 & 12 & 66 & 54 & 15 & 78 & 0.236 \\
\hline Genetics (DNA CGH array) & 18 & 29 & 38 & 1 & 68 & 1 & $<0.0001^{*}$ \\
\hline Blood transfusion & 35 & 12 & 74 & 25 & 44 & 36 & $<0.0001^{\star}$ \\
\hline
\end{tabular}

*Interventions for which there has been a statistically significant change $\left({ }^{*} p<0.05\right)$ in professional view between the two surveys are highlighted in green.

professionals. This may be a reflection of rotational working patterns and genuine uncertainty as to the efficacy of certain treatments:

At times it felt as though treatments were based on which consultant was on call rather than anything else. This was difficult.

Thematic content analysis of professionals' data $(n=4)$ revealed the following six key themes.

\section{Parent availability for clinicians to provide information/gain consent}

One of the barriers to providing information to parents was whether the parents were present:

I will discuss with parents if possible but if no parents available then implied consent. I don't feel I need their agreement to perform.

Professional dilemma as to what constitutes an emergency and is thus exempt from information disclosure/consent under 'best interest' considerations

There are certain interventions that are not always easily categorised as being an emergency. This, in turn, seems to influence the strategy for parental involvement in decision-making:

Depends on context-if time take explicit verbal consent but often an emergency so no consent taken.

Professional dilemma as to the difference between information disclosure and consent and how to proceed should parents not agree with procedure/intervention

There exists a dilemma regarding the interaction between information disclosure and whether this represents consent. Clinicians appear willing in non-emergency situations to provide information and document this in the medical notes. However, even if non-emergency in nature, there is anxiety and uncertainty as to formally gain agreement in a categorical 'yes' or 'no' fashion. This may reflect a degree of medical paternalism and clinical uncertainty in the efficacy of a proposed treatment:

There is lots of evidence of harm, and [it is] uncertain which if any group of babies might benefit. I think parents ought to be given the opportunity to help decide the rigt [sic] approach for their baby.

Concerns also exist on two other fronts. First, the professional concern of overburdening the parents with decision-making:

Parents are overwhelmed by having a sick baby and often express guilt later on about decisions they have been party to... It is unfair for these families to live with the burden of guilt.

Second, there is concern about how to proceed should there be disagreement and whether this might delay treatment:

Good practice to inform parents. Tell them why you are doing the test and the reasons BUT 'what if they say no?

To avoid disagreement, clinicians relied on two concepts: the 'best interest' consideration to justify treatment and the use of 'consensus professional opinion'. As one respondent described:

Consent is important at the point where you would make different decisions based upon parent views.

The implication is that even where clinicians sought a dichotomous outcome from the parents (a 'yes' or 'no'), if this were not in the baby's 'best interest', the clinician would proceed with treatment anyway and, if necessary, 


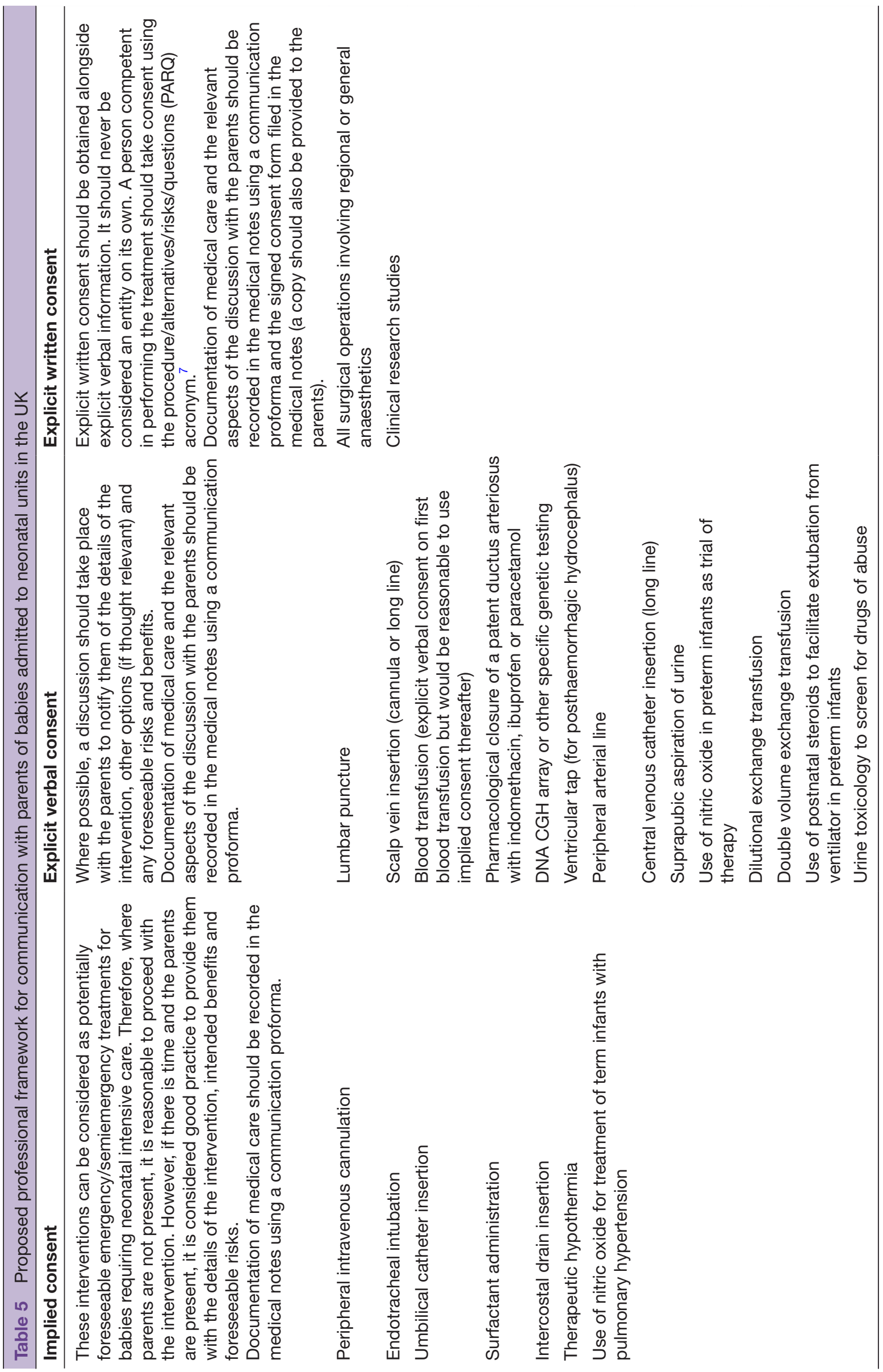


defend this by reference to the 'best interest' standard. Other respondents referred to the importance not of consent per se but of good medical record keeping and consensus where there was professional uncertainty:

Ensuring clear documentation of discussion in the medical record, and I also document multidisciplinary discussion with other colleagues about planned treatment course. Also, the important thing is not necessarily only consent, but also how it is recorded-'written' consent in this case presumably means getting a signature from a parent, but this is well known to not actually represent informed consent.

\section{Time to provide information/obtain consent and the concept of neonatal care as a package}

There was support for provision of information where possible:

For all procedures that are done in a planned way, with sufficient time available to speak to the parents, I feel there should be a conversation conveying all the information which would be given in an explicit consenting process, without actually expecting the parents to respond with a 'yes' or 'no'.

There was also a view that neonatal care represented a multitude of daily interventions, of different risk to benefit ratio, of different efficacy and of different nature and that this should determine how we provide information:

I've taken a baby to do that procedure/management, told the parents they need IV antibiotics, admission to the neonatal unit etc. Unless parents voice concerns, assuming procedure is an essential part of package I am offering (sic).

\section{Risk of treatment and adverse outcome}

Previous clinician experience where a treatment had been associated with an unexpected adverse outcome, where there had not been communication with parents, was of concern:

My views about parental consent with regards to certain key procedures in newborn, including peripheral \& umbilical arterial cannulation, longline insertion have changed because of experiencing adverse incidents due to the catheters/procedures.

\section{Parental burden}

There was concern that neonatal care involved multiple interventions, many of which had uncertain efficacy, and that a balance needed to be struck between paternalistic decision-making using a 'best interest' view versus overinvolvement of the parents in complex decision-making:

Each procedure in [the] list on its own is 'small intervention in context of neonatal care' regarding risk 'acting in best interest of the child'. Parental consent is a secondary activity/consideration. It is unethical to place the apparent burden of decision-making on the parents.

\section{DISCUSSION}

This pilot study demonstrates a degree of concordance between parental and professional views on the types of consent for common neonatal interventions. However, it also suggests variation both within and between the two groups regarding the type of consent required. Further, it demonstrates a change in professional view regarding the type of consent since 2003, with a shift towards preference for explicit verbal consent. The areas of shared thematic analysis between the groups include (1) the risk of burdening the parents with decisions, (2) the dilemma of what constitutes an emergency treatment and (3) the time to discuss treatments.

The study's strengths are that it provides contemporaneous and parallel data regarding parental and professional view on consent. It increases our understanding of where parents and professionals share 'common ground' on this matter. Potential limitations are that it was a single-centre study in the South East of England with a relatively homogeneous parental population. Hence, parental views obtained may not be generalisable to other regions. Further, it includes only a small parent sample and all babies had good health outcomes. The design of the study, which only included babies $>32$ weeks, is likely to have selected a population of parents who had a 'good experience' of neonatal care and thus had a favourable view of the medical team. It would be interesting to establish the views of parents where moderate or serious harm had occurred where the parents are more likely to be critical of the medical team and more likely to pursue legal action. Validation of the results provided in this study, incorporating a larger parental sample size and parents of 'high risk' infants, is needed to better understand how neonatal professionals should communicate complex interventions on the neonatal unit.

Professionals appear uncertain about seeking approval for interventions in a dichotomous 'yes' or 'no' fashion, lest the parents disagree with this. If parental and professional views cannot be reconciled and treatment cannot proceed legitimately through a 'best interest' consideration because the intervention is not an emergency, then the need to involve 'outside' agencies (eg, courts) is of concern. This needs balancing against the requirement to inform parents, where possible, of the need for a treatment, foreseeable risks and benefits, and alternatives. Neonatal professionals seem to take the pragmatic view that the path of least resistance is to provide information (as best one can), act using the 'best interest' standard and provide the intervention knowing that the likelihood is that all will be well. That is, it is unlikely that despite having paternalistic overtones, the parents are 
going to disagree with treatment in the majority of cases, as they have not been asked to agree or disagree and cases that reach court are an exception. Understanding of the characteristics of those interventions that impact on a parent's preferences on whether professionals or parents make the decision is of importance. Data suggest that parents prefer deference to professional view where there is urgency or a high level of medical expertise required. For interventions where there is uncertain or high risk, involvement of foreign bodily fluid (eg, blood transfusion or use of donor maternal expressed breast milk), personal parental experience of the intervention or interventions thought as 'usual' for parents to make decisions on, parents reasonably seem to prefer making these decisions. ${ }^{5}$

What is apparent from these data is that written consent, long held to be the mainstay of providing evidence of informed consent, is not considered the key issue. Rather, it is recognised that effective communication with parents, through implied or explicit verbal information disclosure, is the best route to informed consent. Though this starts to align with the ruling in Montgomery, ${ }^{4}$ the task of how to (1) effectively record the key aspects of information provided and (2) how to gauge what information a particular family deems to be acceptable (at a given time point) remains challenging. It remains limited to effective documentation in the medical record and recognition that information disclosure and consent cannot be achieved through a 'one-size-fits-all strategy'. Each family's needs and each baby's medical circumstances will be different. Some parents may value detailed information and want to participate in decision-making, but the prevailing sentiment of parents in this study was that of trust in professionals and a desire for professionals to retain the burden of decision-making. The recommendations in table 5 represent a suggested 'starting point' for the communication standard required. This enables flexibility and recognises that more detailed communication might be required in certain circumstances.
In conclusion, the data provide preliminary pilot data that might be used to develop a framework for practice as it provides evidence of where consensus exists between parents and professionals. Further, it perhaps highlights that it is parental access to autonomous decision-making rather than autonomy per se that is important.

Acknowledgements VV thanks Pamela Ferguson (Professor of Law), University of Dundee, for her helpful comments on manuscript drafts.

Contributors WV designed the study, obtained ethics approval, collected and analysed the data, and prepared the final manuscript as submitted.

Competing interests $\mathrm{V}$ is a member of a recently convened British Association of Perinatal Medicine (BAPM) working group looking at the issue of information disclosure, communication and consent in neonatal medicine.

Patient consent Obtained.

Ethics approval East Midlands Leicester South research ethics committee (REC reference 16/EM/0152, IRAS ID 202806).

Provenance and peer review Not commissioned; externally peer reviewed.

Open Access This is an Open Access article distributed in accordance with the Creative Commons Attribution Non Commercial (CC BY-NC 4.0) license, which permits others to distribute, remix, adapt, build upon this work non-commercially, and license their derivative works on different terms, provided the original work is properly cited and the use is non-commercial. See: http://creativecommons.org/ licenses/by-nc/4.0/

(C) Article author(s) (or their employer(s) unless otherwise stated in the text of the article) 2017. All rights reserved. No commercial use is permitted unless otherwise expressly granted.

\section{REFERENCES}

1. Carter JD, Mulder RT, Bartram AF, et al. Infants in a neonatal intensive care unit: parental response. Arch Dis Child Fetal Neonatal Ed 2005;90:F109-13.

2. British Association of Perinatal Medicine. Consent for common neonatal investigations, interventions and treatments, 2014 www. bapm.org/publications/ documents/guidelines/procedures.pdf (accessed 23 Aug 2016).

3. Shenoy S, Archdeacon C, Kotecha S, et al. Current practice for obtaining consent in UK neonatal units. Bull Med Ethics 2003:17-19.

4. Montgomery v Lanarkshire Health Board: CSIH, 2015:104.

5. Weiss EM, Barg FK, Cook N, et al. Parental decision-making preferences in neonatal intensive care. J Pediatr 2016;179:36-41.

6. Braun V, Clarke V. Using thematic analysis in psychology. Qual Res Psychol 2006;3:77-101.

7. Sokol DK. Defending the sophisticated consent attack. BMJ 2014;349:g6432. 